Indigenous peoples

\section{Injury prevention and indigenous peoples}

\section{R Berger}

\section{Working with indigenous peoples provides unique opportunities for injury prevention}

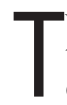
wo articles in this issue of Injury Prevention concern injuries among indigenous peoples, the Navajo or Diné people of the southwestern United States, and the Aboriginal peoples of Western Australia. ${ }^{12}$ The issues raised by these studies have broad relevance. The United Nations estimates there are more than 300 million indigenous people living in over 70 countries. Among them are the estimated 50000 Ainu people of Japan; 80000 Saami people of Scandinavia, the Arctic, and Russia; 600000 Aboriginal peoples of New Zealand and Australia; 3.5 million native peoples of North America (including tribes in the United States, the First Nations of Canada, and the Arctic's Inuit peoples); 13.7 million nomadic peoples of Africa; and 148 million indigenous peoples of China and the countries of South and East Asia. Many of the challenges and solutions for working with indigenous people apply to research and action involving other culturally diverse populations, whether cross nationally or within national borders.

There are a number of commonalities among indigenous peoples. These include cultures extending for thousands of years; experiences of exploitation, attempts at forced assimilation, and large scale neglect of human rights, health problems, and social needs; deeply held spiritual beliefs and practices; and increasing efforts to obtain international recognition and protection for their peoples and cultures. Equally important is the enormous diversity, even within individual countries. Canada is home to the Métis, Inuit, and over 600 First Nations peoples. There are more than 550 federally recognized tribes in the United States. When the first white settlers arrived in Australia, there were 300000 Aboriginal peoples speaking over 250 languages. Also, there can be profound differences in lifestyle within individual tribes or cultural groups. To address the rising motor vehicle injury rate among Aboriginals in Western Australia, for example, we need to know much more about the varied lifestyles of both the urban and rural populations. Are economic conditions improving in rural areas, resulting in more vehicle miles traveled in cars and an increased use of all-terrain vehicles? Or are the occupant injuries increasing because of increased commuting to distant jobs via poorly maintained buses and trucks? Are the Aboriginal people who suffer pedestrian injuries in urban areas newly arrived city dwellers who have not learned "street-smarts", homeless people with substance abuse problems, or low income families living in population dense neighborhoods with dangerously situated schools and play areas? $?^{45}$

For certain mechanisms of injury, indigenous peoples often have dramatically higher injury rates compared with the non-indigenous population in their countries. As noted in the paper by Phelan et al, the 1995 age adjusted motor vehicle related death rate for Navajos was more than five times that of the white population in the United States. For Aboriginal people in Western Australia, the road injury hospitalization rate was nearly twice that of the non-Aboriginal population. In Northern Saskatchewan, Canada, where two thirds of the population is Native (Woodland Cree, Dene, and Métis), suicide and homicide rates among 15-24 year olds are three to five times greater than the remainder of the provincial population. ${ }^{6}$ In the United States, the rate of fire related deaths in one Indian Health Service (IHS) area is six times greater than the national average. ${ }^{7}$ Poverty is clearly an important factor. ${ }^{8}$ Many indigenous people suffer high rates of unemployment (exceeding $70 \%$ in some communities); are homeless or live in overcrowded and substandard housing; reside in communities without adequate medical, fire, police, or human services; and receive inadequate education. Higher rates of injury are not entirely a reflection of economic disadvantage, however. Fire related injury rates, for example, are increased in households where people smoke cigarettes, abuse alcohol, use wood stoves for heating and cooking, and prepare foods by frying (thereby creating smoke that triggers nuisance alarms and subsequent disconnection of smoke detectors). Subsistence living, such as fishing in freezing temperatures and in stormy weather, can be fraught with danger from drowning and hypothermia. The high proportion of pickup trucks among Navajo families ( $40 \%$ of vehicles in one survey) contributes to passenger injuries as both children and adults are unrestrained in the rear cargo areas. Certain types of injury are a result of racism, manifested through both neglect and acts of commission. Over $70 \%$ of Native Americans in the United States who were victims of violence reported that the offenders were non-Native.' High rates of incarceration, and an absence of preventive measures, contributed to the high death rate of indigenous people held in police and prison custody in Australia. ${ }^{10} 11$

The role of alcohol misuse as a contributing factor to high rates of injury among indigenous peoples is a complicated one. Phelan et al report that alcohol was involved in less than $8 \%$ of pediatric motor vehicle related injuries. Since blood alcohol levels were not collected from the drivers of all the involved vehicles, this figure obviously must be viewed with skepticism. Among Navajo victims of pedestrian and hypothermia deaths, alcohol intoxication was frequent and severe. ${ }^{12}$ A national survey in Australia of Aboriginal peoples and Torres Strait Islanders found that over half identified alcohol abuse as the main health problem in their community. ${ }^{13}$

Several of the challenges in conducting studies concerning indigenous peoples are illustrated by the articles of Phelan et al and by Cercarelli and Knuiman. One challenge is obtaining reliable numerator data by ethnicity. It is unclear, for example, how patients were categorized as "Aboriginal" when admitted to hospitals in Western Australia. If by self report, Cercarelli and Knuiman suggest that it is increasingly acceptable to self identify as "Aboriginal". Also, changes in access to medical care can alter hospitalization rates. Members of the Navajo Nation can be treated not only at United States IHS facilities, but private, self pay, and governmental health insurance options allow many individuals access to health care facilities outside the IHS hospital discharge database. Another difficulty is obtaining accurate denominator data. The Census Bureau in the United States has acknowledged that minority populations, including Native Americans, are routinely undercounted. It has proposed statistical corrections to make more accurate estimates, but political forces have prevented any such adjustment. In Australia, the Bureau of Statistics did not separately enumerate Aboriginal people before 1971.2

Why should the readers of Injury Prevention consider injuries among indigenous people a priority? There are reasons 
of social policy, social justice, and treaty obligations. There are dramatically high rates of specific mechanisms of injury. There are also unique opportunities for prevention. Many indigenous people recognize the importance of preventing injuries, both from personal experience as well as familiarity with the data on injury rates. Their communities bring their cultural and intellectual wealth and their willingness to implement and evaluate community based interventions. There often is a commitment to addressing the underlying causes of injury, to consider both categorical interventions and a community development approach. ${ }^{6}$ The latter involves building local skills in community development, strengthening support systems for people and families in crisis, increasing access to mental health services, fostering healthy early childhood development, ensuring meaningful community participation in government decisions affecting their lives, and promoting economic development. Working with indigenous people also provides an opportunity to gain important insights into our own lives and values. For example, after listening to a lecture on demographic trends, a Native American audience member commented: "I must disagree with you on one point, professor. Our people do not have extended families. Your people have contracted families".

How do we address issues involving indigenous peoples without appearing discriminatory or patronizing? We must be willing to make a long term commitment to establish trust and build personal relationships. We must form partnerships with community members, including them in leadership roles at every step of the process, from setting priorities, designing studies and interventions, analyzing and disseminating results. ${ }^{14}$ We must provide training, funding and technical assistance, so communities can develop their own injury prevention programs. ${ }^{16}$ We must also learn as much as possible about the history, cultural beliefs and practices, and social, political, and economic conditions of the people with whom we are working. ${ }^{17-20}$ I attended a presentation by "national injury experts" at an Indian pueblo where community members were urged to install gates to prevent toddlers from falling down stairs and window guards to prevent falls from multistoried apartments. The presenters had not noticed that all the homes were single story dwellings with earthen floors.
In conducting studies among special populations, not only must we consider ethical standards as they apply to individuals (obtaining informed consent, insuring confidentiality, weighing risks and benefits), ${ }^{21}$ but also ethical conduct as it relates to communities. Research has the potential to inflict harm on communities by violating cultural taboos, revealing cultural or ceremonial secrets, exploiting intellectual property, and stigmatizing communities. In addition to minimizing potential risks, researchers can seek to maximize the benefits of research to communities. Potential benefits include providing valuable information, reducing injuries, teaching research and public health skills, employing community members, purchasing equipment for use in the community, and reimbursing community organizations for overhead costs. All research projects should have written approvals from appropriate community entities, such as the local health board, tribal council, or community institutional review board. In addition to obtaining human studies approval from their own academic institution, Phelan's group obtained consent from the local tribal government (a tribal chapter house), as well as from the Navajo Area Health Board and Health Research Review Board.

On an international level, we need to share knowledge and experiences about injury problems and injury prevention among indigenous peoples. The World Health Organization's Injury Prevention Program $^{22}$ and the United Nations Permanent Forum on Indigenous Peoples (which held its first meeting in Tehran in May of this year) could jointly sponsor an international meeting. Perhaps the venue could be the next International Conference on Injury Control to be held in Vienna in 2004, coming as it does in the last year of the United Nations Decade of Indigenous People. While "outsiders" could contribute a great deal in the way of information and technical expertise, it would be indigenous peoples who would create the agenda and establish the priorities for research and action.

\section{Injury Prevention 2002;8:175-176}

\section{Author's affiliation}

L R Berger, Clinical Associate Professor of Pediatrics, University of New Mexico, Albuquerque

Correspondence to: Dr Lawrence Berger, 1335
Bryn Mawr Drive NE, Albuquerque, NM 87106-1101, USA; bergerlaw@msn.com

\section{REFERENCES}

1 Phelan KJ, Khoury J, Grossman DC, et al. Pediatric motor vehicle related injuries in the Navajo Nation: the impact of the 1988 child occupant restraint laws. Inj Prev

2002;8:216-20.

2 Cercarelli LR, Knuiman MW. Trends in road injury hospitalization rates for Aboriginal and non-Aboriginal people in Western Australia 1971 to 1997. Inj Prev 2002;8:21 1-15

3 MacKellar A. Deaths from injury in childhood in Western Australia, 1982-1992. Med J Aust 1995;162:238-42.

4 Johnson SJ, Sullivan M, Grossman DC. Injury hospitalizations among American Indian youth in Washington. Inj Prev 1999;5: 119-23.

5 Sugarman JR, Grossman DC. Trauma among American Indians in an urban county. Public Health Rep 1996;111:321-7.

6 Feather J, Irvine J, Belanger B, et al Promoting social health in Northern Saskatchewan. Can J Public Health 1993;84:250-3.

7 Kuklinski D, Berger LR, Weaver JR. Smoke detector nuisance alarms: a field study in a Native American community. National Fire Protection Association Journal 1996; September/October:65-72.

8 Faelker T, Pickett W, Brison RJ. Socioeconomic differences in childhood injury: a population based epidemiologic study in Ontario, Canada. Inj Prev 2000;6:203-8.

9 Greenfield LA, Smith SK. American Indians and crime. Washington, DC: US Department of Justice, Office of Justice Programs, Bureau of Justice Statistics, 1999

10 Thomson NJ, McDonald D. Australian deaths in custody, 1980-1989. 1. Relative risks of Aborigines and non-Aborigines. Med J Aust 1993:159:577-81.

11 McDonald D, Thomson NJ: Australian deaths in custody, 1980-1989. 2. Causes. Med J Aust 1993;159:581-5.

12 Gallaher $M M$, Fleming DW, Berger $L R$, et al. Pedestrian and hypothermia deaths among Native Americans in New Mexico: between bar and home. JAMA 1992;267: 1345-8.

13 Condon JR, Cunningham J. Premature mortality in Aboriginal adults in the Northern Territory, 1979-1991. Med J Aust 1997; 166:278-70.

14 Mathews JD. The Menzies School of Health Research offers a new paradigm of cooperative research. Med J Aust 1998; 169:625-9.

15 Davis SM, Reid R. Practicing participatory research in American Indian communities. Am J Clin Nutr 1999;69(suppl):755S-9S

16 Smith R, Dellapenna A, Berger L. Training injury control practitioners: the Indian Health Service Model. The Future of Children 2000;10:171-84(spring/summer).

17 Canada reconciliation site (www.ainc-inac.gc.ca/gs/index_e.html).

8 Australia reconciliation site (www.austlii.edu.au/au/orgs/car)

19 Jackson LR, Ward JE. Aboriginal health: why is reconciliation necessary? Med J Aust 1998; 170:437-40.

20 Berger LR. A combination of traditional wisdom and public health could help. West J Med 1999;171:14-15. 21 Ellerby JH, McKenzie J, McKay S, et al.
Bioethics for clinicians: 18. Aboriginal cultures. Can Med Assoc J 2000;163:84550.

22 Krug EG, Butchart A, Peden M. A new department for injuries and violence prevention at the World Health Organization. Inj Prev 2001;7:331-3. 